\title{
2015 Gabriella E. Molnar-Swafford Pediatric PM\&R Awards
}

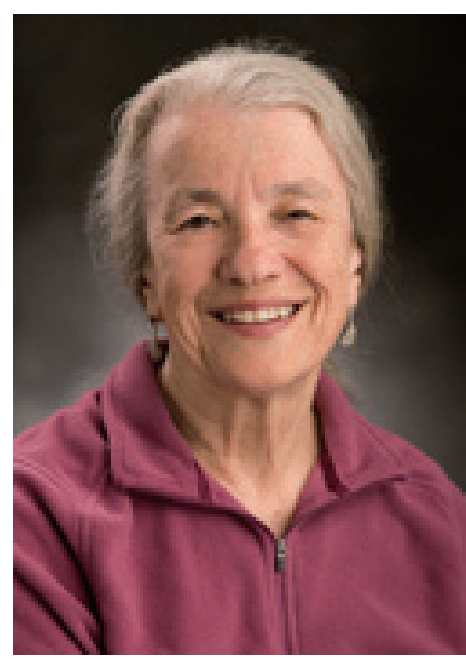

\section{Gabriella E. Molnar-Swafford Pediatric PM\&R Lifetime Achievement Award}

Virginia Simson Nelson, M.D., M.P.H is a passionate advocate, teacher, clinical researcher, mentor, volunteer, and dedicated clinician who has served as a leader in Pediatric Rehabilitation Medicine (PRM) for decades.

Dr. Nelson initially trained as a pediatrician at Stanford University, obtained a Master's in Public Health at the University of Michigan (U of M) and then completed a residency in Physical Medicine and Rehabilitation (PM\&R). She spent her entire career at U of M, rising through the academic ranks and achieving clinical Professor in 2002. She currently continues as a Professor Emerita faculty member as of January 1, 2015.

From a research perspective, Dr. Nelson, has received nine grants and published over 50 peer reviewed publications. She has authored 23 book chapters and lectured worldwide - including Portugal, India, China, East Africa, Finland, Canada and many other countries. Her research and expertise include the ventilator-dependent child, brachial plexus, arthrogryposis, orthotics and prosthetics, and ethics in pediatric rehabilitation. She has served as a peer reviewer for multiple journals, a grant reviewer for the Amer- ican Academy of Cerebral Palsy and Developmental Medicine (AACPDM) and serves as an associate editor for the Journal of Pediatric Rehabilitation Medicine.

From an education perspective, Dr. Nelson is known as an outstanding, teacher, mentor and leader. Her mentors include department chairs, academic researchers, and other leaders in the pediatric rehabilitation field. She has received several prestigious awards for her teaching and mentorship has also provided guidance to nurses, therapists and medical students. In 2009, she received the American Association of Physical Medicine and Rehabilitation (AAPM\&R) Distinguished clinician award.

Her volunteerism and advocacy locally, nationally, and internationally is an example for all. She has served as a founder and camp director for 25 years for the University of Michigan Trails Edge Camp for children with ventilators. In addition, she has served on a myriad of state boards, school boards and community advisory committees. Nationally, she served on the board of directors AACPDM, as secretary of Board of Directors of AACPDM, on multiple AACPDM and AAPM\&R committees, and as the secretary, Vice President and President of the AAPMR Pediatric Special Interest Group (currently called the Pediatric and Developmental Disabilities Council). Internationally, since 2001, she spends one month a year providing pediatric rehabilitation services, training and leadership in East Africa.

\section{Gabriella E. Molnar-Swafford Pediatric PM\&R Research Grant Recipient}

Congratulations to Gerald H. Clayton, $\mathrm{PhD}$ from Denver Children's Hospital on receiving the Molnar Research Grant award for his project titled Quantitative Encephalography as a Tool for Evaluation of Adolescent Concussions. Specific objectives are to:

1. Determine individual baseline qEEG p300/p50 amplitudes and auditory response times in a population of healthy adolescent soccer athletes without a history of recent head injury and assess the population mean, median and variability. A 
subset of athletes will be retested at a standard interval to determine test-retest reliability for this instrument. In the event that any of these athletes sustain a concussion during the competitive season, re-assess measurements in the acute phase of recovery.

2. Evaluate the ability of qEEG P300/p50 amplitudes and auditory response times to discriminate between adolescent patients with chronic ongoing postconcussive symptoms and uninjured adolescents of similar age.

3. Assess the association between symptom improvement and changes in qEEG p300/p50 amplitudes and auditory response times during the standard course of care for adolescents with chronic ongoing post-concussive symptoms. 